Saudi Journal of Oral and Dental Research

Abbreviated Key Title: Saudi J Oral Dent Res

ISSN 2518-1300 (Print) |ISSN 2518-1297 (Online)

Scholars Middle East Publishers, Dubai, United Arab Emirates

Journal homepage: https://saudijournals.com

\title{
Maxillary Root Displacement to the Infraorbital Recess Following Dental Extraction: Case Report
}

\author{
Yaser AlNatheer ${ }^{1}$, Ahmad AlOmar ${ }^{2}$, Amal AlShamrani ${ }^{3}$, Razan Tokhtah ${ }^{3 *}$ \\ ${ }^{1}$ Resident, Department of Oral and Maxillofacial Surgery, College of Dentistry, King Saud University, Riyadh, Saudi Arabia Saudi Arabia \\ ${ }^{2}$ Associate Professor, Department of Oral and Maxillofacial Surgery, College of Dentistry, King Saud University, Riyadh, Saudi Arabia \\ ${ }^{3}$ Dental Interns, College of Dentistry, King Saud University, Riyadh, Saudi Arabia
}

\begin{abstract}
DOI: $\underline{10.36348 / \text { sjodr.2021.v06i01.002 }}$
| Received: 20.12.2020 | Accepted: 30.12.2020 | Published: 08.01.2021
\end{abstract}

*Corresponding author: Razan Tokhtah

\section{Abstract}

The anatomical relationship between the floor of maxillary sinus and maxillary posterior teeth always possess a challenge in dentistry, especially during the endodontic and extraction procedures. Maxillary sinus often pneumatize between the molar roots and results in proximity between them. Odontogenic sinusitis incidence is of $10 \%$ to $12 \%$ of a wellrecognized phenomena. The most common cause is foreign body displacement into the sinus. The most common foreign body in the maxillary sinus is an extracted maxillary tooth followed by a displaced root. This article reports a case in which a root was displaced to the most medial superior margin of the maxillary sinus. The palatal root was displaced during extraction of the left maxillary second molar and was retrieved after three days of the incidence.

Keywords: maxillary sinus, root displacement, Caldwell-Luc, Schneidarian membrane.

Copyright (C) 2021 The Author(s): This is an open-access article distributed under the terms of the Creative Commons Attribution 4.0 International License (CC BY-NC 4.0) which permits unrestricted use, distribution, and reproduction in any medium for non-commercial use provided the original author and source are credited.

\section{INTRODUCTION}

The anatomical relationship between the floor of maxillary sinus and maxillary posterior teeth always possess a challenge in dentistry, especially during the endodontic and extraction procedures. Maxillary sinus often pneumatize between the molar roots and results in proximity between them [1]. Sinusitis can appear as a result of iatrogenic perforation of the floor or spread of infection from periapical region to the sinus due to the perforation of the sinus membrane (Schneidarian membrane). The most common foreign body in the maxillary sinus is an extracted maxillary tooth followed by a displaced root or root fragments [2]. In the radiograph, this foreign body will appear as a dense rounded radiopacity that will be an excellent niche for fungal and bacterial growth. Clinically, the patient might present with the following symptoms: oro-antral fistula, nasal discharge, pain, obstruction, headaches that intensify in the evenings while bending, and an unpleasant odor [3]. Management usually includes removal of the dental infection and sinus closure followed by a three-to-four-week trial of antibiotic therapy with adequate oral and sinus flora coverage. Studies suggest the following as the main treatment options: Caldwell-Luc (CL) operation, Functional Endo- scopic Sinus Surgery (FESS), dental extraction (treatment), or combinations of these [4].

\section{CASE REPORT}

A 30-year-old patient with no known medical history nor allergies, heavy smoker, referred from a private clinic after extraction of left maxillary second molar two days prior to his visit in our clinic. Dental history revealed that the patient presented in a private clinic to extract the upper left second molar which was endodonticallty treated and badly broken (figure1). During extraction, the palatal root fractured, and the treating dentist could not visualize the root in the socket so he requested a periapical radiograph (PA) with an orthopantomogram (OPG) to locate the root (figure2, 3 ). After the root was located in the socket, the dentist attempted another trail to remove the broken root fragment but he could not retrieve it. Another PA was taken; the root could not be located (figure4). The dentist referred the patient to our facility (Department of Oral and Maxillofacial Surgery, King Saud University). The patient presented with no signs or symptoms. An informed consent was obtained from the patient. Upon intra-oral examination, the root could not be located in the socket, and there was an oro-antral communication. In the OPG, a well-defined radiopaque mass, of the same radiopacity of a tooth structure is located near the left inferior medial maxillary sinus roof that is $4 \times 3 \mathrm{~mm}$ in dimensions (figure5). Cone Beam Computed Tomography (CBCT) was requested, the 
palatal root was identified at the superior medial border of the left maxillary sinus (figure6). A decision was made to retrieve the tooth fragment and to manage it surgically through the Caldwell-Luc approach. Local anesthesia was administered using lidocaine $2 \%$ with epinephrine 1:100,000. An incision of $4 \mathrm{~mm}$ was made in the buccal vestibule inferior to the previous incision. Periosteal elevation and multiple irrigation and suction through the existing socket were done (figure7). Root fragment was retrieved successfully (figure8). A buccal flap advancement to close oro-antral communication and suturing (figure9). Antibiotics (amoxicillin/clavulanate potassium and Metronidazole) were prescribed for 7 days, analgesics when needed, and nasal decongestants. Post-operative instructions (sinus percussions) were given to the patient: to quiet smoking, to avoid drinking from straw, avoid sneezing and mouth rinsing, in addition to use cold packs in the same day and warm packs for the next few days to overcome edema of the cheek. Patient was scheduled for a follow up visit after one week. In the follow up visit, patient presented with no signs or symptoms. Intra-oral examination showed a small nodule that is $1 \mathrm{x} 1 \mathrm{~mm}$ in the buccal vestibule that appeared after the surgery and recession of gingiva around the distal root of the left maxillary first molar. Plan was to apply a desensitizing agent on the distal root and a recall visit after one month. In the recall visit, patient presented with no signs and symptoms, the surgical site was intact with no signs of wound dehiscence (figure11, 12).

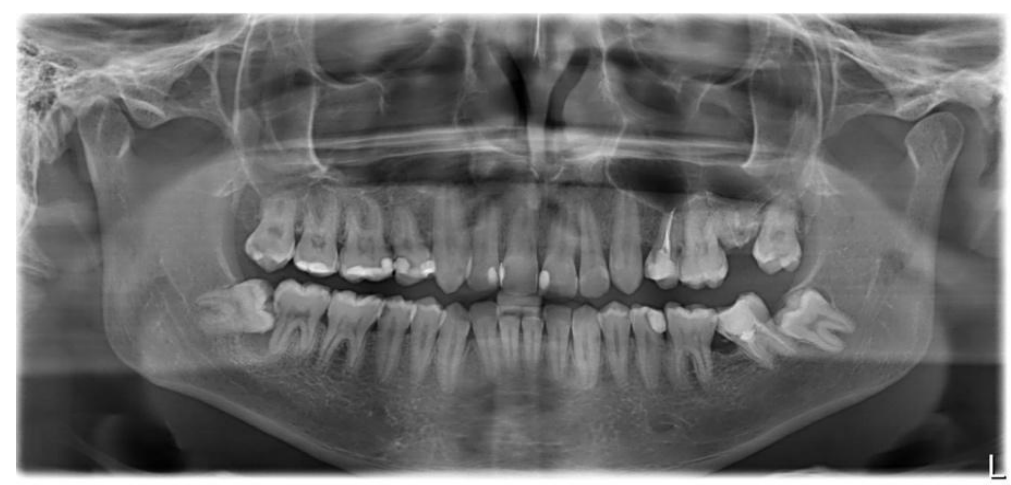

Fig-1: OPG before the extraction showing the badly broken \#27

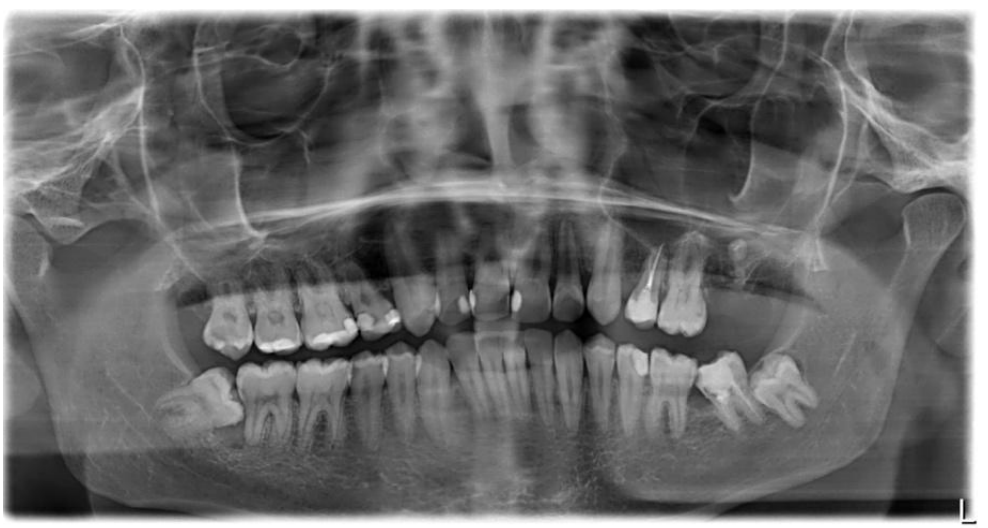

Fig-2: OPG showing the fractured palatal root in the socket

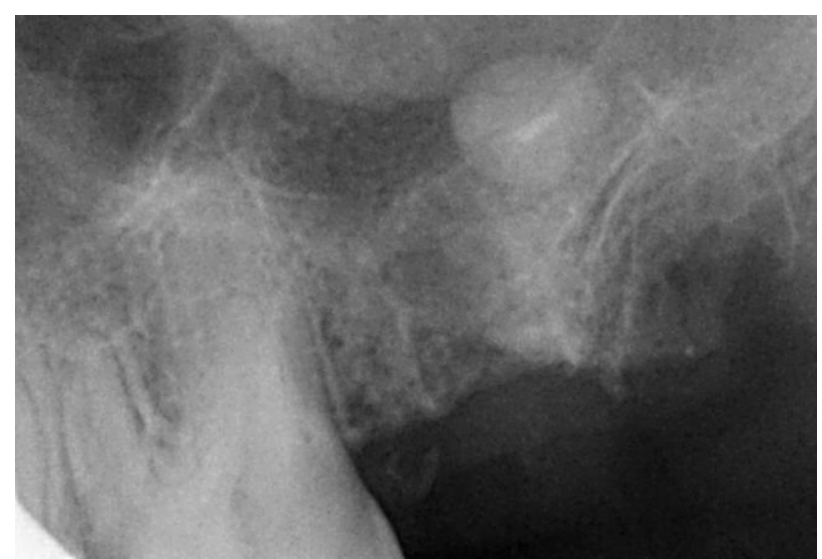

Fig-3: PA showing the fractured palatal root 


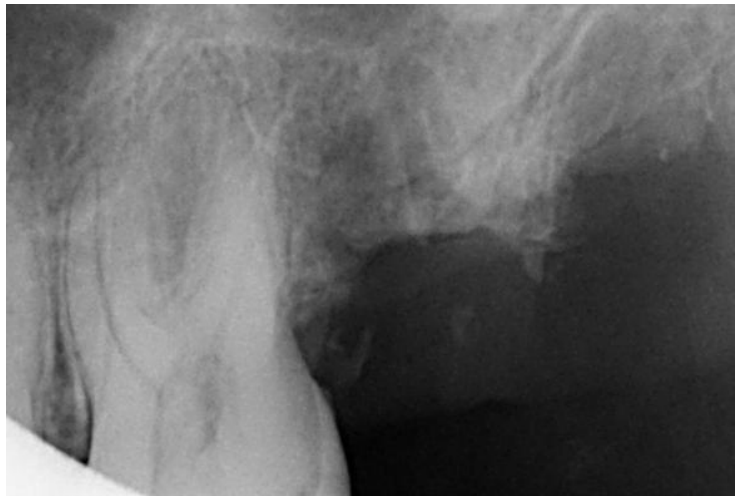

Fig-4: PA showing the root has displaced from the socket

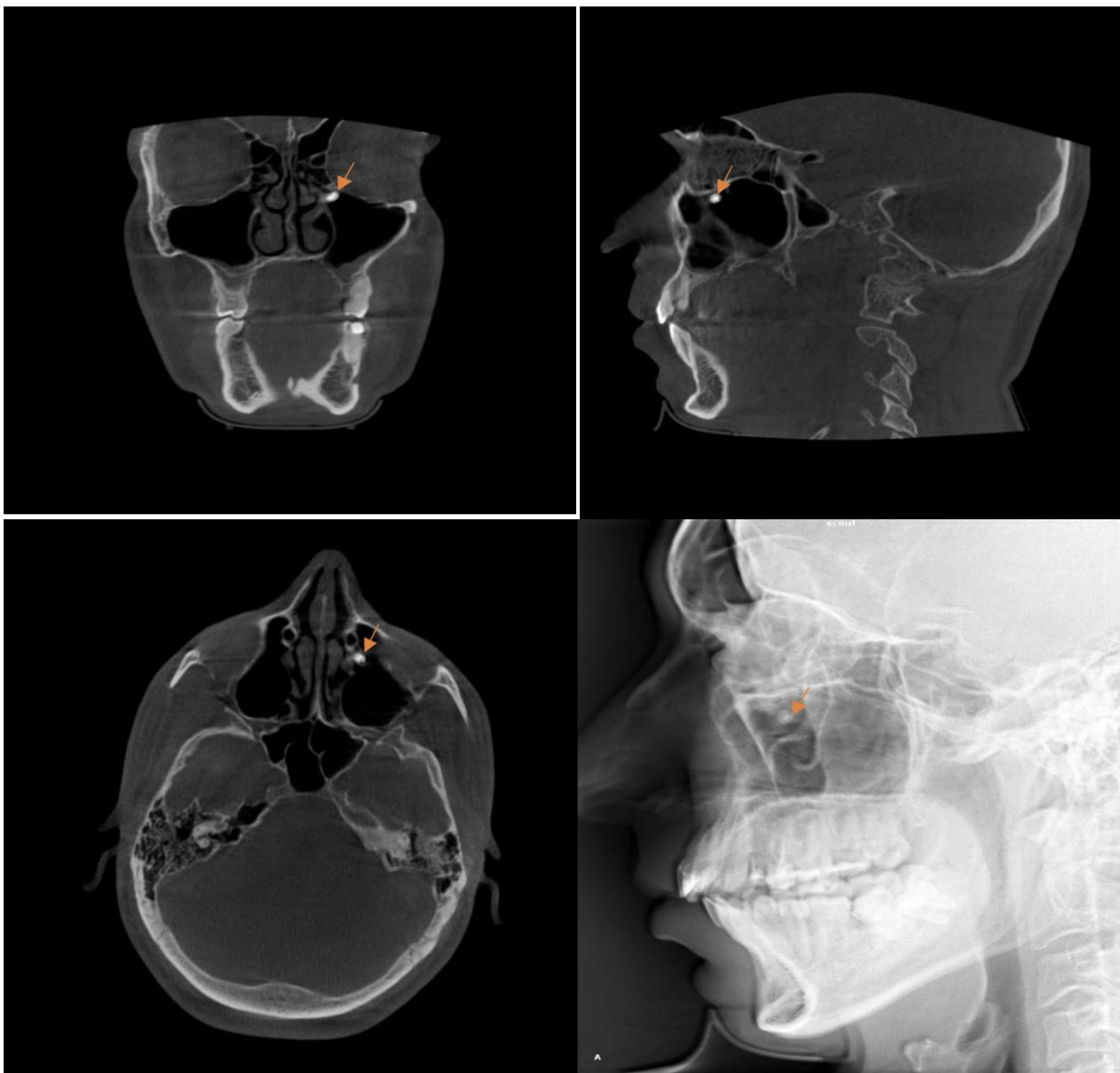

Fig-5: CBCT showing the displaced root (arrow) in different sections 
Yaser AlNatheer et al; Saudi J Oral Dent Res, Jan, 2021; 6(1): 9-14

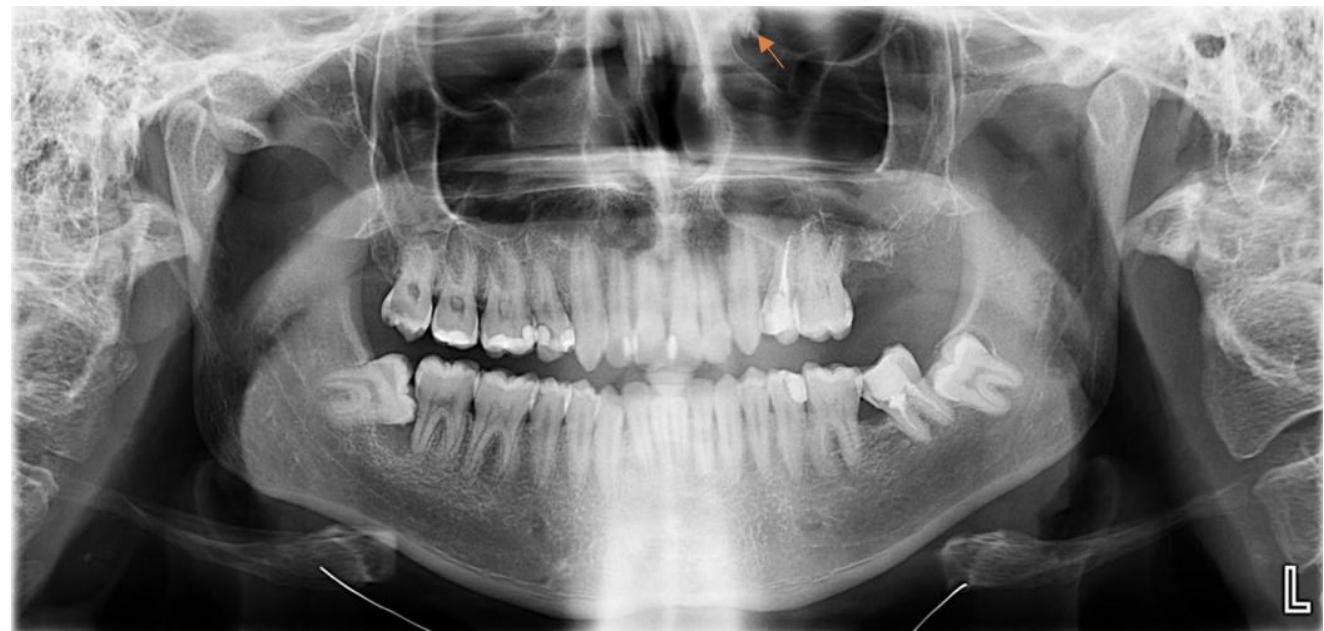

Fig-6: Preoperative OPG showing the displaced root fragment in the most medial superior position in the left maxillary sinus (arrow)

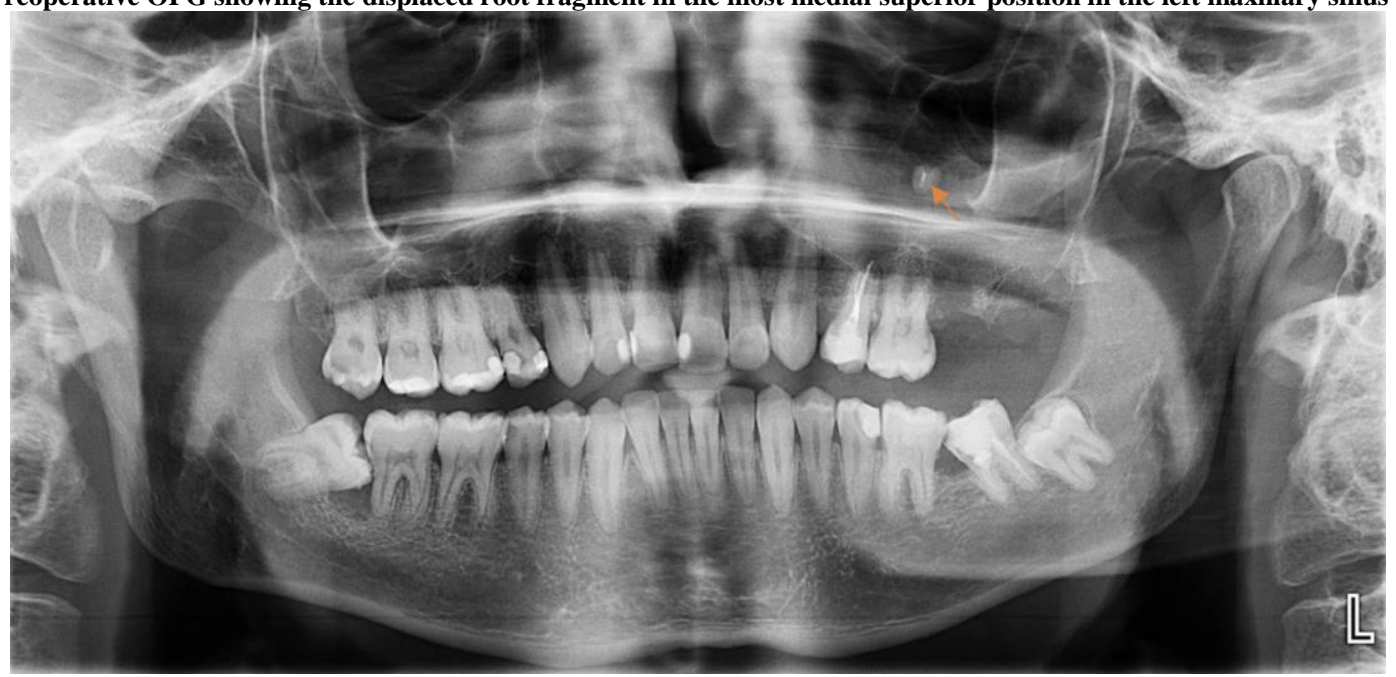

Fig-7: Intra-operative OPG after irrigation showing the root has moved from its previous position (arrow)
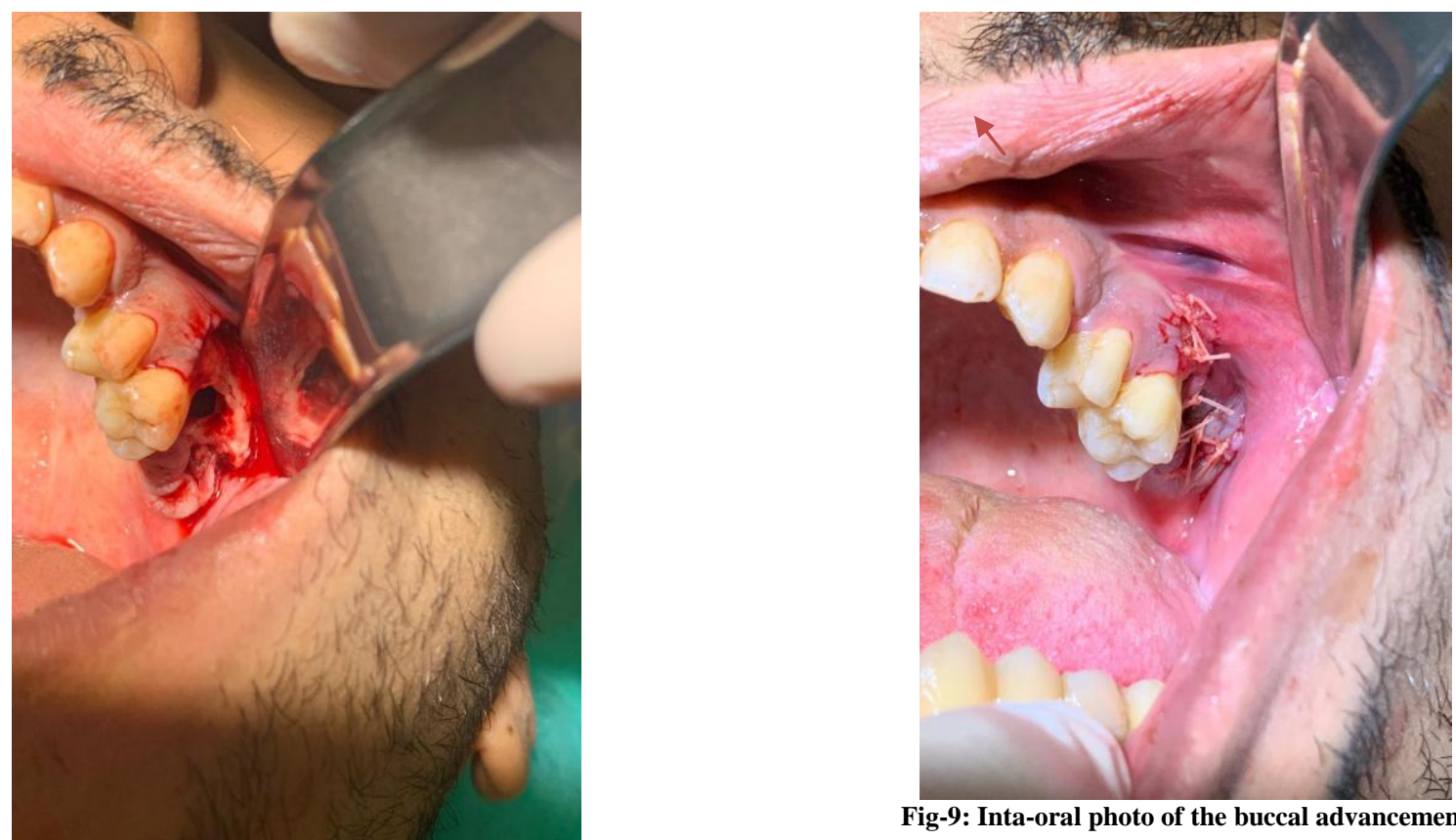

Fig-9: Inta-oral photo of the buccal advancement

Fig-8: Inta-oral photo after periosteal reflection of the flap 


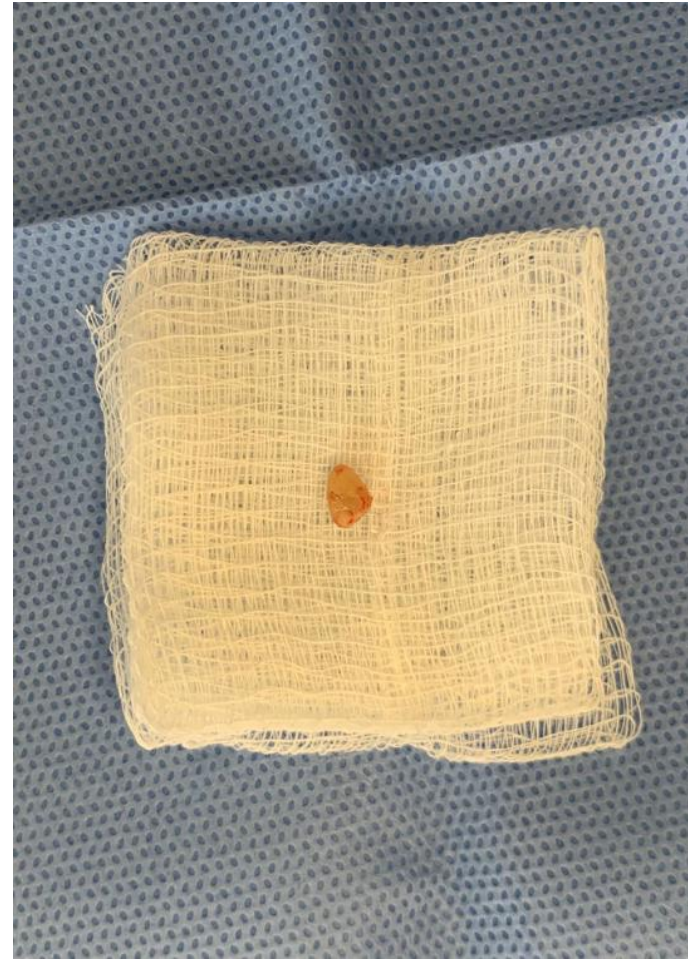

Fig-10: The root fragment retrieved

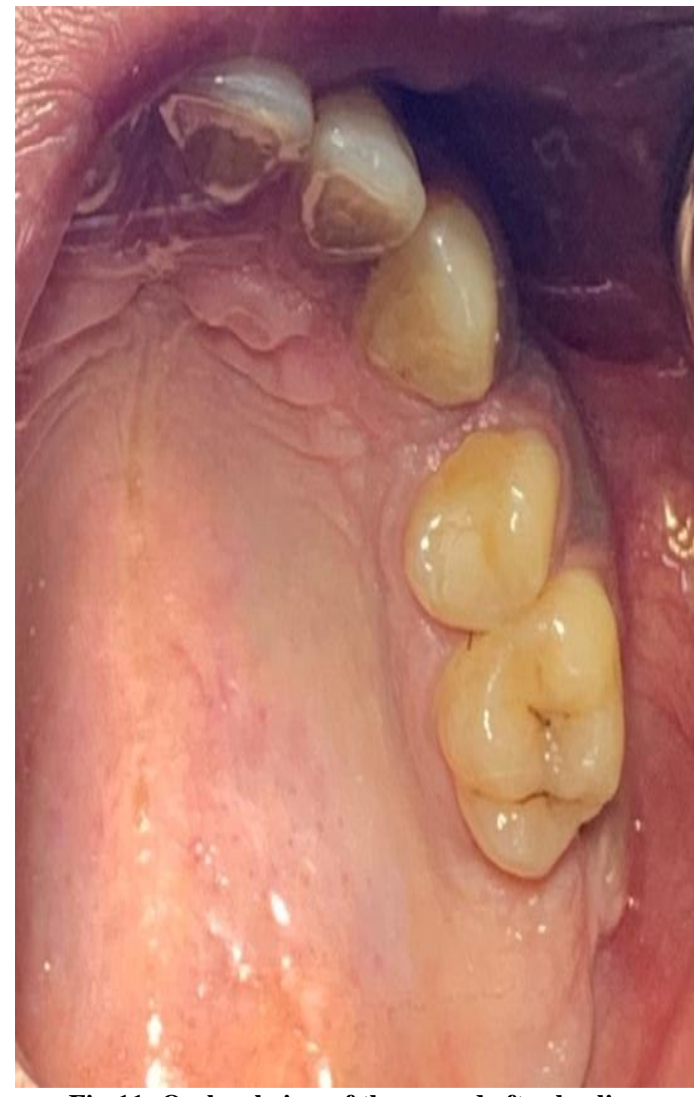

Fig-11: Occlusal view of the wound after healing

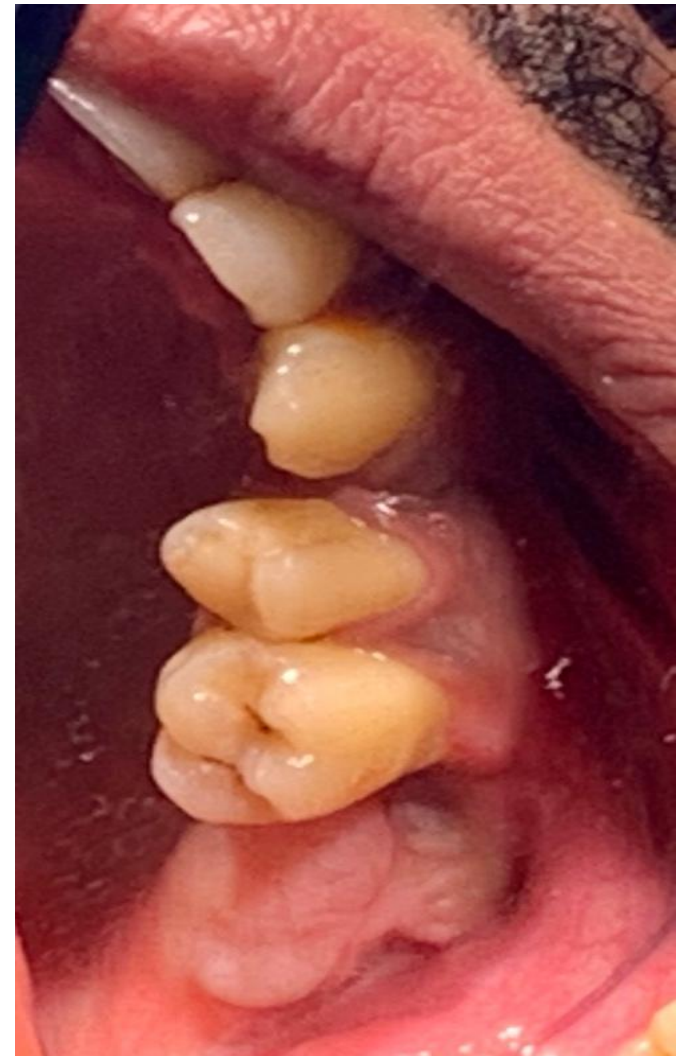

Fig-12: Lateral view of the wound after healing

\section{DISCUSSION}

Removal of roots in the antrum can be done through two surgical approaches, particularly the alveolar approach at the tooth socket site and the Caldwell-Luc approach through the canine fossa [5, 7]. The alveolar method retrieves the root that lies extramucosally, in one of the tissue planes without penetrating the antral mucosa. Most of the roots gravitate to the maxillary sinus floor or near the tooth socket. Exploring the socket and locating the root can be done easily through this procedure. Notwithstanding, displaced roots in the nasal ostium or between apices of the vital tooth may also be difficult via this approach [3]. The Caldwell-Luc surgery is creating a bony window through the anterior wall of the sinus in the canine fossa area via a vestibular incision [6]. The Caldwell-Luc operation is indicated for treating antralpolys, acute and chronic sinusitis, malignant tumors of the maxillary sinus, and retrieving a displaced tooth or root fragment [8]. The main disadvantage of this procedure is the multiple complications that can be addressed. For instance, facial swelling or numbness, facial paresthesia in the suborbital area, hemorrhage, suborbital neuralgias, fistula, dental devitalization, dacryocystitis [9]. With this purpose in mind, good surgical techniques and gentle tissue retraction are essential. Besides, avoiding infraorbital nerve damage and avoiding any overextended antrostomy and any bony crack during surgery [10]. Oroantral communication is an abnormal communication that mostly resulted from the tooth extraction $[5,11]$. Using 
Yaser AlNatheer et al; Saudi J Oral Dent Res, Jan, 2021; 6(1): 9-14

palatal flap, buccal advancement flap, or buccal fat pad flap are the commonly used techniques for closure of oroantral communication [12,13]. In the University of Malaya, a broad-spectrum antibiotic is prescribed postoperatively, e.g., amoxicillin, doxycycline, cefuroxine, and sultamicillin with a mild analgesic [5]. The topical nasal decongestant $1 \%$ ephedrine, $0.5 \%$ phenylephrine hydrochloride, and $0.05 \%$ oxymetazoline hydrochloride solution can be used. Constricting the sinusoids in the nasal mucosa, but secondary vasodilation can occur following the use of nasal drops. The long-term use of decongestant is not preferable. It has been manifested to result in ciliary loss, epithelial ulceration, inflammatory cell infiltration, and subepithelial edema in the nasal mucosa of the animal study model [14]. The reason of root displacement to the most superior medial margin of the maxillary antrum could be justified by forceful extraction or negative pressure by the patient that caused the small root fragment to be "suctioned" to that position.

\section{CONCLUSION}

The Caldwell-Luc approach is used successfully to remove the root in the maxillary sinus. Therefore, to reduce the incidence of complications it should be noted cald-well Luc procedure is a delicate process. In like manner, closure of the oroantral fistula is another important step of the treatment and the further prosthodontic rehabilitation must be taken into consideration.

\section{REFERENCES}

1. Fry, R. R., Patidar, D. C., Goyal, S., \& Malhotra, A. (2016). Proximity of maxillary posterior teeth roots to maxillary sinus and adjacent structures using Denta scan®. Indian journal of dentistry, 7(3), 126-130. https://doi.org/10.4103/0975-962X.189339

2. Pelinsari Lana, J., Moura Rodrigues Carneiro, P., de Carvalho Machado, V., Eduardo Alencar de Souza, P., Ricardo Manzi, F., \& Campolina Rebello Horta, M. (2011). Anatomic variations and lesions of the maxillary sinus detected in cone beam computed tomography for dental implants.
Clinical Oral Implants Research, 23(12), 13981403.

3. Rode, M., Podboj, J., \& Kogoj-Rode, M., 2004. Sinus maxillaris mycetoma of odontogenic origin: case report. Brazilian Dental Journal, 15(3), 248250.

4. Aukštakalnis, R., Simonavičiūtè, R., \& Simuntis, R. (2018). Treatment options for odontogenic maxillary sinusitis: a review. Stomatologija, 20(1), 22-26.

5. Langdon, J. (1976). The maxillary sinus and its dental implications (dental practitioner handbook, no. 18). Journal of Dentistry, 4(5), 244-245.

6. Lee, F. (1978). Management of the displaced root in the maxillary sinus. International Journal of Oral Surgery, 7(4), 374-379.

7. Smail, D. B. (2003). Contemporary Oral and Maxillofacial Surgery. New York State Dental Journal, 69(8), 55.

8. Ball, I. A., \& Manton, S. L. (1991). Root agenesis in developing canines as a complication of intranasal antrostomy. Oral surgery, oral medicine, oral pathology, 72(5), 509-513.

9. Bajan, A., Sarafoleanu, C., Melinte, V. G., \& Decuseara, R. (2020). Indications of the CaldwellLuc procedure in the era of endoscopic sinus surgery. Romanian Journal of Rhinology, 10(39), 78-84.

10. Low, W. (1995). Complications of the caldwell-luc operation and how to avoid them. ANZ Journal of Surgery, 65(8), 582-584.

11. Chongruk, E. (1989). Radiographs and tooth roots in maxillary sinus. J Dent Assoc Thai, 39: 88-95.

12. Von, Wowern, N. (1982). Closure of oroantral fistula with buccal flap: Rehrmann versus Môczár. International Journal of Oral Surgery, 11(3), 156165.

13. Hanazawa, Y., Itoh, K., Mabashi, T., \& Sato, K. (1995). Closure of oroantral communications using a pedicled buccal fat pad graft. Journal of Oral and Maxillofacial Surgery, 53(7), 771-775.

14. Suh, S., Chon, K., Min, Y., Jeong, C. and Hong, S. (1995). Effects of Topical Nasal Decongestants on Histology of Nasal Respiratory Mucosa in Rabbits. Acta Oto-Laryngologica, 115(5), 664-671. 